\title{
Computer Quiz Games in General Chemistry for Engineering Majors in an English as a Second Language Environment
}

S. S. Ling ${ }^{1}$, F. Saffre ${ }^{2}$, D. L. Gater ${ }^{3}$, L. Bt. Halim ${ }^{4}$, and A. F. Isakovic ${ }^{5}$

${ }^{1}$ Department of Chemistry and Preparatory Program, Khalifa University of Science and Technology (KUST), Abu Dhabi, PO 127788, United Arab Emirates

2 Technical Research Centre of Finland (VTT), Vuorimiehentie 3, 02044 Espoo, Finland

${ }^{3}$ Institute of Education, University College London, London, United Kingdom

${ }^{4}$ Faculty of Education, National University of Malaysia, Bangi, Malaysia

5 Physics and Astronomy Department, Colgate University, Hamilton, NY, 13346, USA

\section{ABSTRACT}

Computer quiz games are introduced to improve teaching and learning in a freshman engineering chemistry course in an English-as-a-Second-Language (ESL) environment. These quiz games are developed and implemented as a supplemental and augmentative tool to enhance traditionally delivered lectures. The paper shows an increase in students' motivation and compare the performance between students who participated in computer quiz games, a paper-based quiz or neither activity. Assessment of the effectiveness of quiz games in learning is conducted via a proposed novel chemistry achievement test, Freshman Engineering Chemistry Aptitude Test and an attitude questionnaire. The findings contribute to our understanding of the role of game-based learning in students' achievement in chemistry and their motivation and attitudes towards learning general chemistry at a university within an ESL environment, while the computer games developed are useful in all English based Chemistry classes.

\section{KEYWORDS}

Introductory Chemistry, games, English as a second language, student centered learning, computer-based learning, hands-on learning.

\section{INTRODUCTION AND MOTIVATION}

Freshman engineering chemistry is considered difficult by a non-negligible fraction of students [1] and is sometimes reported as a course with lower than desired or expected achievement [2]. The factors leading to this include diminished interest in general science courses, and sub-adequate instruction for large classes [3,4]. As switching from traditional to completely interactive, student-centered teaching methodology is not easy at most institutions [5], we developed a novel approach, augmenting traditional course delivery through a relatively small portion of class time on a weekly basis. We also aimed to encourage deeper student involvement and provide tools enabling self-paced learning [6,7]. Beyond these globally relevant issues, many local 
students (UAE and broader Arabian/Persian Gulf region) acquire a limited understanding of scientific concepts at all educational stages, partly due to traditional teaching methodology, and partly due to overreliance on rote learning $[1,8,9]$, making the goals and objectives of this work worthy of regional attention [3, 8].

Since the 1970s, interactive engagement methods have been introduced in science classes [10, 11, 12], including, but not limited to: cooperative learning [10, 11], peer instruction [12, 13] and student team-achievement division (STAD) method [6]; educational computer game-based learning [14, 15]; e-learning [16 - 18]; and web-based learning, some of which relies on gaming [19-21]. Common to all of these methods is the introduction of an in-class activity that keeps students engaged in the learning (and, sometimes, evaluation) process, in contrast with traditional approaches of students' passive presence while instructors deliver content.

With the current trend of increasing use of online learning tools likely to continue, our approach, computer quiz games (CQGs), is one potential pathway towards increasing the use of both modern computing and interactive engagement learning methods in science education. One critical issue in promoting learning is the activation of students' self-regulating systems that aid in the development of motivation [22 - 25], thus affecting academic achievement by influencing behaviors such as attendance, participation, question-asking, advice-seeking, studying, and participation in study groups [25, 26].

\section{GAME ASPECTS AND ROLE OF QUIZ GAMES IN COURSE DELIVERY AND SYLLABUS}

Classroom-based games are considered effective educational tools [27-29]. Simple game quizzes can increase flexibility in the classroom, permit group or independent work, and introduce collaboration and/or competition. Numerous applications of game principles to enhance learning have been reported [27-34]. Some recent developments include: Jeopardy-type games [33]; "Go Chemistry" and card games [28]; exercise games [34]; and Game-based Review Module [29].

The CQGs are weakly incentivized as follows. The Introductory General Chemistry for Engineering Majors (GenCHEM) course grade comprises contributions, from lab (25\%), mid-semester exams (20\%), traditional quizzes $(25 \%)$ and final exam $(30 \%)$. The overall grade from traditional quizzes could be improved through CQGs by performing better than $\sim 67 \%$ of the class on quiz games, with a maximum possible improvement of 2.5 points towards 100 points for the overall course grade.

\section{CHEMISTRY LEARNING IN AN ESL ENVIRONMENT}

Basic language proficiency plays an important role in course delivery and learning in science [38-42], as poor language proficiency increases chance of conceptual misunderstanding [41]. Despite having nearly all university instruction in English, 
difficulties in English proficiency are considered a very common issue for college education in the UAE and MENA (Middle East and North Africa) [41, 42]. This is affected in unpredictable ways by a large international multi-generational migrant population, which creates an increasingly heterogeneous population in secondary and university education that does not map onto other well-studied populations (e.g. USA, Europe, Australia, or Asian Far East). The educational environment in the UAE differs from that encountered by ESL students studying in English-speaking countries, in that education may be the only context in which English is the predominant, day-to-day language. The population of students majoring in engineering disciplines at Khalifa University is unique in several ways: $>98 \%$ are ESL speakers, and are of diverse socio-economic backgrounds; students are either UAE nationals ( 85\%) or come from a diverse group of predominantly MENA-region expatriates ( 15\%). Within the overall set of ESL issues encountered elsewhere, reading comprehension is the skill lagging most. Simultaneously, there exist substantial gaps in several areas of elementary (pre-calculus) mathematics. These skill deficits hamper learning from both the students' and instructors' perspectives, which motivates development of teaching and learning strategies that enhance, or augment, language skills alongside chemistry content [41, 43].

\section{RESEARCH QUESTIONS}

The following research questions have been explored in this report:

1. Is it possible to design, implement CQGs for a traditional classroom with minimal interruption to classroom activities and without a decrease in learning gains?

2. What is the relationship between ESL performance, learning gains and chemistry course performance?

3. Could a suitable test of general chemistry knowledge be developed for use in post-test vs pretest measurements (e.g. as measured by Hake's Gain)?

4. Does the implementation of CQGs improve learning gains compared with two control groups: students with paper-based quizzes and students who have neither CQGs nor paper quizzes?

5. Does the implementation of CQGs affect students' attitude towards and motivation for learning chemistry?

\section{METHODOLOGY}

Students registered in the GenCHEM course in three consecutive semesters (Sem I, Sem II, Sem III), participated in the study. Students in Sems I and II were randomly assigned to groups $\mathrm{X}$ (answering questions via CQGs) and $\mathrm{Y}$ (answering questions from the same question set on paper) of approximately equal population size. Student-specific weekly performance was anonymized. Both CQGs and paper quizzes (PQs) were 
administered simultaneously in class for $\sim 10$ minutes per week for 10 weeks during a 15-week semester. Group $Z$ comprised students registered in the same course in Sem II, for whom neither CQGs nor PQs were administered. At the beginning of each semester, all groups were addressed with a demographic survey and a chemistry achievement pretest in the form of the Freshman Engineering Chemistry Aptitude Test [42] (FECAT, see supplementary information). At the end of each semester, all groups took the FECAT again, as well as an attitude survey.

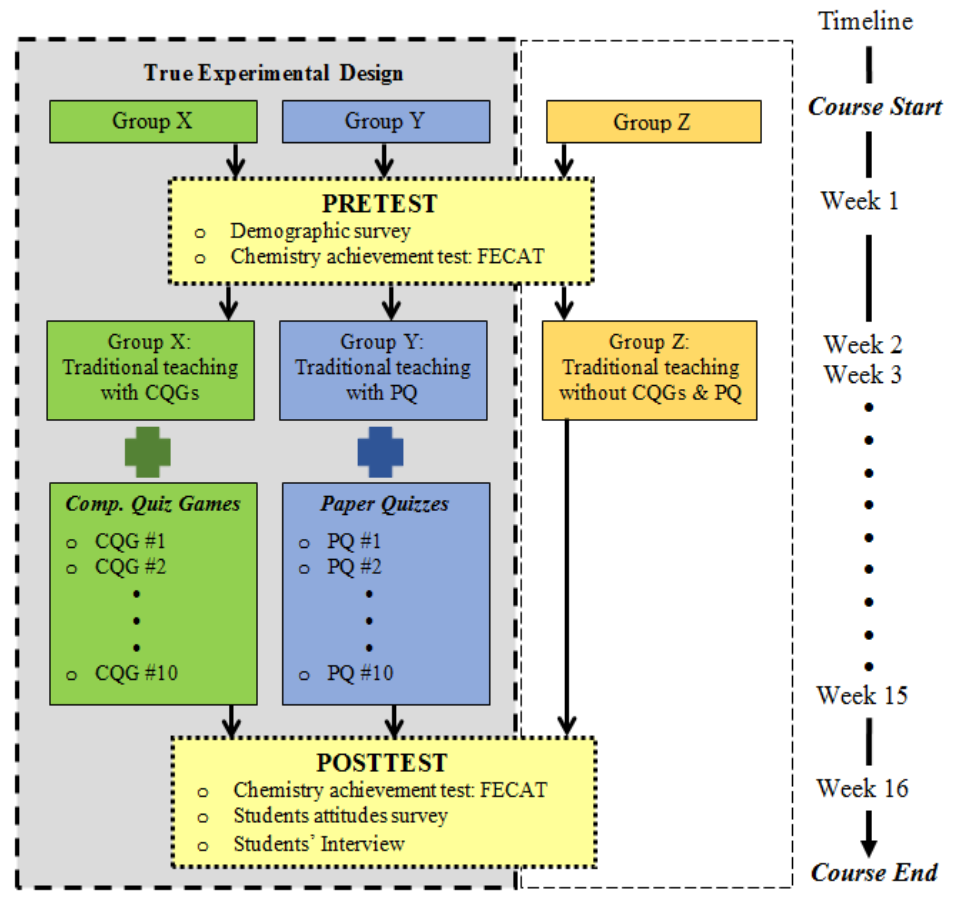

Figure 1. Experimental design for the game-based learning in engineering freshmen chemistry course

In addition, selected students representing all demographic categories and performance levels were interviewed after the end of the semester. In addition to our own motivation to use control groups, a need for varied control groups is felt in some previous studies [43-45].

A. Chemistry Quiz Game (CQG)

Upon starting the CQG, the student is presented with a dialog frame and asked to confirm their identity (for record-keeping), after which the game rules are displayed. The student starts the quiz by clicking the button labelled "Start when ready!" on the frame displaying the rules. The student sees a matrix of 9 questions. Simultaneously, a countdown timer begins and is displayed in a frame titled "Referee" alongside the updated 
score. Each element in the matrix is a clickable button, allowing the student to select a question.
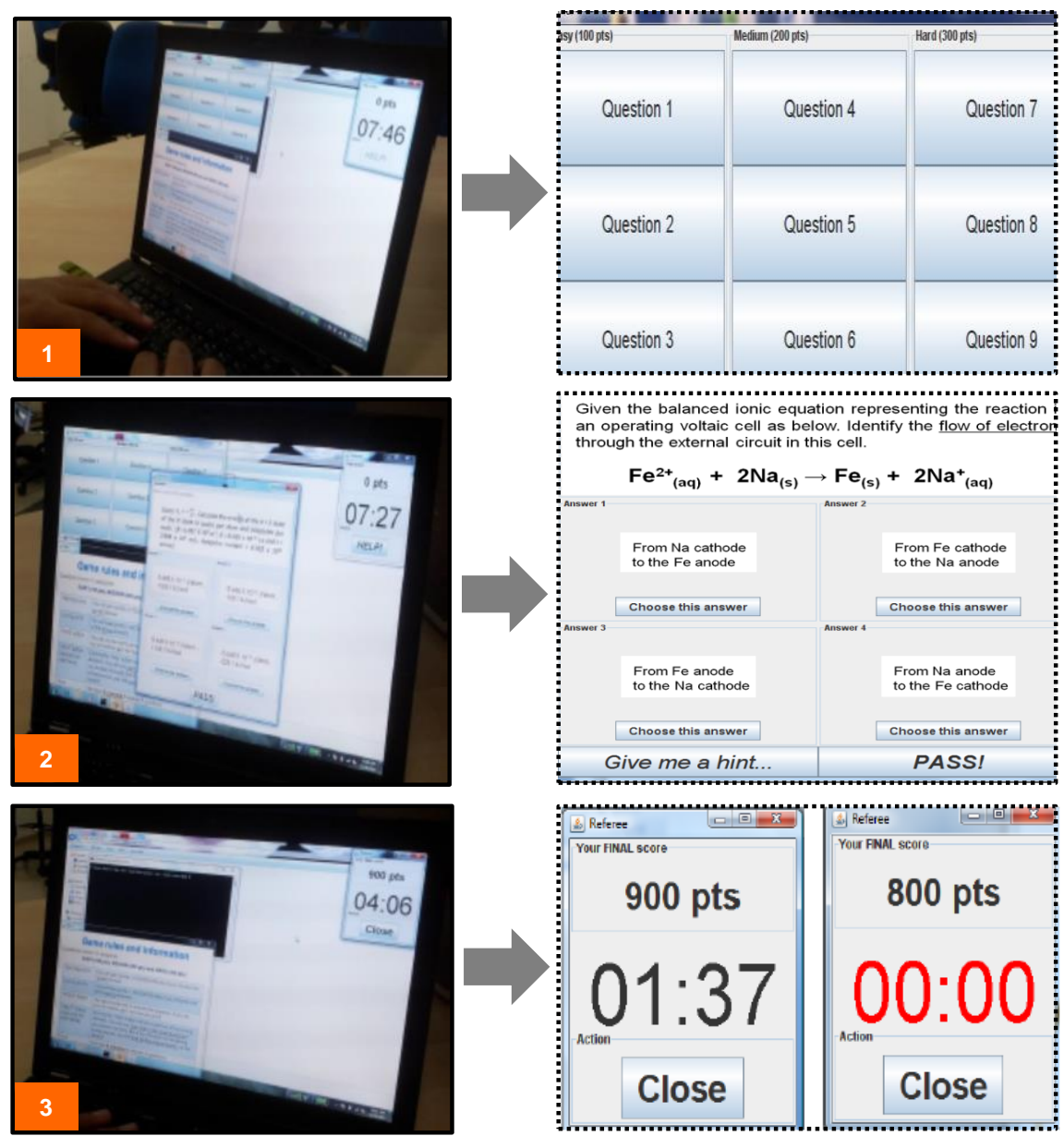

Figure 2. Details of the implementation on students' laptops. Images on the left show the snapshots in time of student's progression through the phases of the game. Images on the right are a more detailed look.

Each button deactivates after one click, to prevent the same question being selected twice. Clicking a question button prompts the opening of a question frame, which is organized as follows: at the top is the question, containing text and/or graphics; underneath are 4 possible answers (also text and/or graphics based), each of which is a clickable button. In the current implementation, there is only one correct answer. Answers are randomly organized in the frame on each run, to avoid bias or recognizable patterns, and to reduce the likelihood of cheating in the classroom environment. At the bottom of the question frame are three additional buttons, "hint", "pass", and "help". "Hint" provides a clue, "pass" leaves the question without incurring a point penalty, and "help" removes two wrong answers. Clicking the "help" or "hint" buttons incurs a point 
penalty specified in the rules. If the correct answer is selected, points are added to the total score. If the "pass" button or a wrong answer is clicked, the correct answer is displayed before the quiz continues. The game ends when either the timer reaches zero or the student has attempted to answer the maximum allowed number of questions (currently five of nine). At this point, all interactive features are disabled, the final score is computed and displayed, and the result is written into a file (linked to the student's username). Supporting materials contain a modified, online version of two such quiz games.

Within standard game classifications [35, 36], our CQGs are quantitative games; the score is prominently displayed and responds to student entries throughout the game. They are also finite games, (a limit of five choices out of nine possible questions). Also, winning is the goal; students learn the anonymized top class score and the distribution of scores between finishing one game and playing the next. One difference with traditional computer games is that students in this study could not choose when to play the game. Future faculty users could allow students to play at individually chosen times. The students are free to define their own strategy which "easy", "medium" and "hard" questions to answer. The CQGs are 10 minutes long or less for two reasons: (a) to minimize disruption of the traditional classroom; and (b) to allow variation of instructional activities on a 10-12 minute time-scale, as recommended elsewhere [31, 32, 37].

\section{B. Freshman Engineering Chemistry Aptitude Test (FECAT)}

The FECAT has been developed in parallel with the CQG, primarily as a tool to measure learning gain via post-test vs pre-test assessment. The test follows a typical USstyle freshman engineering majors chemistry syllabus, similar to the corresponding $\mathrm{KU}$ course (KU has had ABET accreditation since AY 2014/15). There is no overlap between the FECAT, CQG questions, and course assessment instruments. FECAT could also be used: (a) as an independent course assessment instrument; (b) to assess student readiness to take a freshman engineering chemistry course, (c) to help instructors tailor lectures, if used as a diagnostic test in the first week. The test contains 36 multiple choice questions (see supporting information), the content and wording of which is based on Bloom's Taxonomy [46]. Questions are classified into five categories: (1) basic properties of matter and fundamental laws of nature; (2) chemical properties of elements and compounds; (3) chemical reactions; (4) heat and other energy concepts in chemistry; (5) atomic structure and chemical bonds. A thorough analysis of the FECAT performance, including analysis of individual categories is provided in a separate report [47]. For the student population participating in this study, FECAT has a typical Cronbach Alpha 
coefficient between 0.72 and 0.81 , depending on semester, indicating that reliability is good $[49,50]$. We expect that further applications and some improvements of the test will lead both coefficients to increase toward more desirable values of 0.85 or 0.9 , respectively, which would make the reliability "very good" or "excellent". Normality tests for each question showed that skewness and kurtosis of 30 questions is within the recommended range, given $a=0.01$, so the critical $z$ value is \pm 2.58 [50]. Questions $7,15,21,23,26$ and 30 do not satisfy these criteria, but are close. Within the five categories, each category had only one question not satisfying the above criteria, except the "atomic structure and chemical bonds", which had two such questions. Nonetheless, the values of Hake's gain and other results in this report have included these questions, since their impact on increase or decrease on the gain is much smaller than the uncertainty.

\section{Students' Attitudes Survey}

The attitudes survey is based on selected sets of questions about "enjoyment of chemistry lessons", adapted from the Test Of Science-Related Attitudes questionnaire (TOSRA) [51]; and "motivation" questions, based on Science Motivation Questionnaire (SMQ) [52], [43]. A five-point Likert-type scale with Strongly Agree (SA) to Strongly Disagree (SD) was used as the response format of the survey.

D. Interview Protocol

Interviews were conducted after the end of the semester. Interviewees ( $n=29)$ were selected from a range of backgrounds (i.e. gender, nationality, course performance). Interviews comprised of two parts: questions answered on a Likert scale and several openended questions. Interviews were recorded, transcribed, and viewed and checked by interviewees for clarification.

\section{RESULTS AND DISCUSSION}

\section{A. Demographic Results}

Demographic details, including number of students per semester and per group, gender and nationality, are shown in Table 1. Note that groups $\mathrm{X}$ and $\mathrm{Y}$ were initially equal in size, but incomplete datasets for some students were removed from analysis (e.g. if a student completed less than 7 of the 10 CQGs or PQs, or was absent for the post-test and/or attitude survey). Due to a lack of available information before the study began regarding English literacy and math skills, students were simply randomized to groups $\mathrm{X}$ and $\mathrm{Y}$, resulting in an uneven distribution of student abilities across these three categories. In addition, there were noticeable changes in the male-female ratio between the three semesters, that were beyond experimenters' control. 
Table 1. Number of students per semester, per group, gender and nationality; three consecutive Sem(esters)

(CQG - computer quiz game; $\mathrm{PQ}$ - paper quiz)

\begin{tabular}{|c|c|c|c|c|c|c|}
\hline \multirow{3}{*}{$\begin{array}{c}\text { Semester } \rightarrow \\
\text { Group X } \rightarrow \\
\text { (CQGs) }\end{array}$} & \multicolumn{2}{|c|}{ Semester I } & \multicolumn{2}{|c|}{ Semester II } & \multicolumn{2}{|c|}{$\begin{array}{l}\text { Semester III (group Z) } \\
\text { Neither CQG nor PQ }\end{array}$} \\
\hline & male & 12 & male & 36 & Male & 43 \\
\hline & female & 22 & female & 27 & Female & 51 \\
\hline & UAE national & 25 & UAE national & 58 & UAE national & 83 \\
\hline & foreign & 9 & foreign & 5 & Foreign & 11 \\
\hline \multirow{4}{*}{$\begin{array}{c}\text { Group Y } \rightarrow \\
\text { (PQs) }\end{array}$} & male & 10 & male & 37 & & \\
\hline & female & 26 & female & 21 & & \\
\hline & UAE national & 24 & UAE national & 51 & & \\
\hline & foreign & 12 & foreign & 7 & & \\
\hline
\end{tabular}

\section{B. Hake's gain on FECAT}

All three groups (X, Y and $\mathrm{Z}$ ) showed learning gains in the FECAT post-test vs pretest methodology, as shown in Fig. 3. In Sem I, the Hake gain for group X (with CQGs) was slightly larger compared with group Y (with PQs), whereas groups X and Y both had similar positive Hake gain in Sem II. Although the differences were small, it must be noted that as a result of imperfect randomization, students in group Y had higher overall GPA, math skills and IELTS scores (English skills) compared with students in group X. In comparison, group $Z$, from Sem III (with neither CQGs nor PQs) showed lower Hake gain compared with groups $\mathrm{X}$ and $\mathrm{Y}$, while having nearly identical math and IELTS scores and the overall GPA. Next, we discuss the FECAT Hake gain as a function of two independent variables: cumulative IELTS (comprising contributions from reading, writing, listening and speaking) and Final Exam scores. There is increase in the gain as the cumulative IELTS score increases, up to the IELTS value of 6.5. This is understandable in that higher IELTS score is frequently correlated with increased performance and GPA [55]. Also, students with IELTS $=7.0$ and higher, often had such high pretest scores that they were unable to have significant Hake gain. 

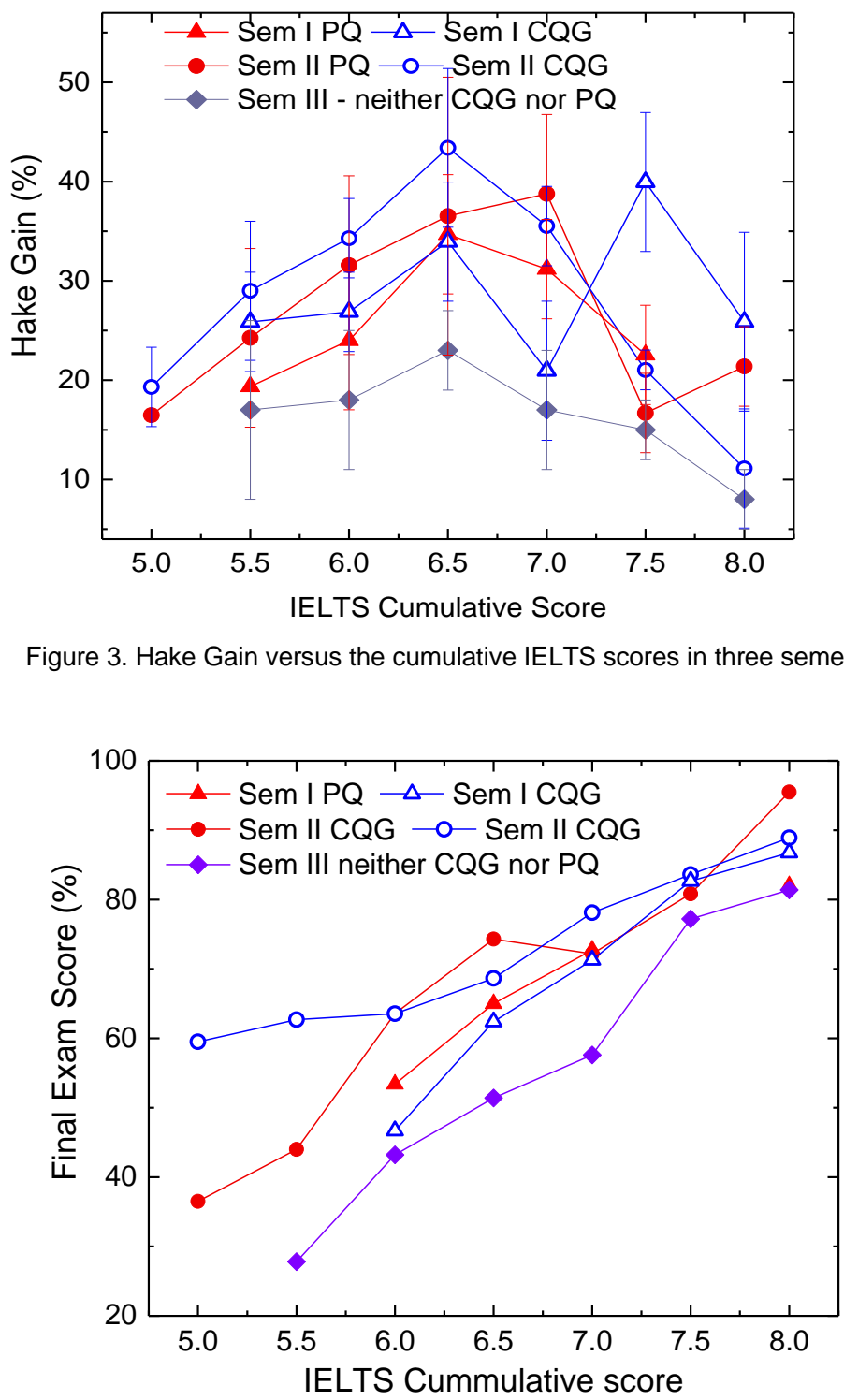

Fig. 4 A comparison of final exam scores across IELTS-Reading values in this study

The results in Figs. 3 and 4 also show that both CQGs and PQs could be effective tools in boosting student performance, especially for the IELTS bands where majority of students fit (IELTS $6.0-7.0$ ). The change of the final exam score shows more steadily rising function of the IELTS score, as one would expect for the assessment that students 
were actively preparing for through biweekly and mid-term assessments throughout the semester (unlike FECAT). We make the following observations:

B.1 Group $Z$ students, who did not use either CQG or PQ at any point in the semester, show lower Hake gain, demonstrating the activity itself (whether it is CQG or PQ) helps students achieve higher gain regardless of the type of activity.

B.2 The relatively small difference in Hake gain for individual IELTS performance level, between CQG (group X) and PQ (group Y) is ascribed to at least two factors: (a) the presence of nearly identical motivating factors, (b) accidental, hard to control, skills imbalance in the makeup of $\mathrm{X}$ and $\mathrm{Y}$ groups, in favor of the $\mathrm{Y}$ group.

Another method of comparing students' progress is to examine how many students increase (move up) in their performance percentile group over the course of the semester. Fig. 5 displays such data for the second semester of the study (similar data exist for the first semester). The shift of the number of students from a performance

Figure 5. Comparison between pretest and posttest; the number of students as a function of the performance percentile on the FECAT

average of about $40^{\text {th }}$ percentile to $70^{\text {th }}$ is visible in both panels, with some quantitative differences between CQG and PQ student groups. It is worth pointing out there are at least five different curricula (US, UK, Canadian, IB and local state schools) currently implemented in UAE high schools, thus the context for the FECAT design and 
future use is not just as a research instrument, but also as a standardized freshmen college readiness assessment instrument.

\section{Students' Attitudes Survey}

Responses for one of the motivation questions/statements, "I find learning chemistry interesting", are summarized in Figures 6 (by group and semester). We select this particular question because its distribution of responses is very similar to the distributions of responses for the two enjoyment questions; namely, "Chemistry lessons are fun", and "I enjoy the activities we do in chemistry class" (date for which are not shown for brevity, but are available upon request). Most students agreed or strongly agreed with this statement in both CQG run semesters. These data are very encouraging regarding the relatively positive effect of the CQGs on student motivation and enjoyment.

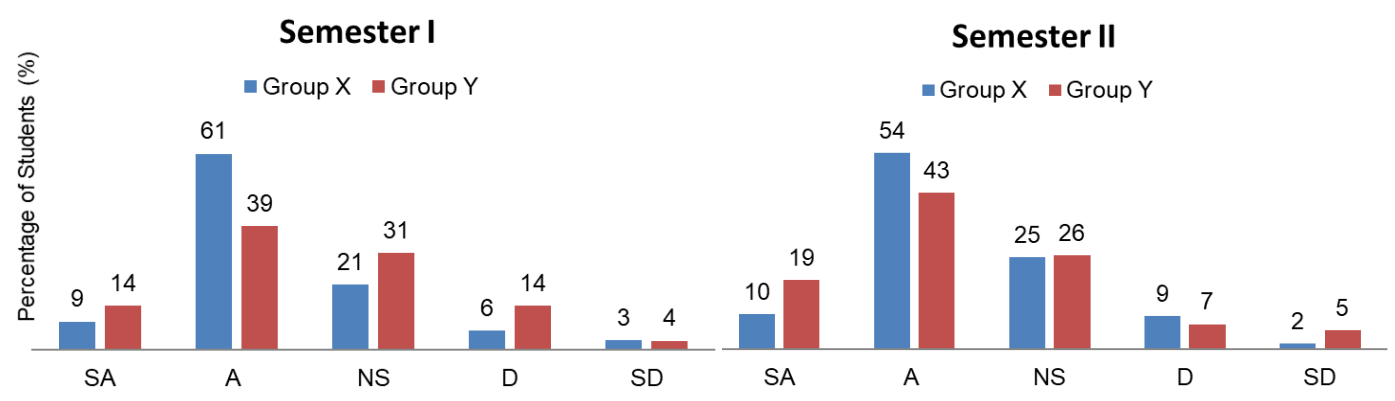

Figure 6. Comparing students' response to "I find chemistry interesting" for: (a) Semester I, and, (b) Semester II, computer quiz games $(X)$ and paper quizzes $(Y)$. (SA) - strongly agree, ..., (SD) - strongly disagree

Data for a number of other questions are available upon request, and are not shown here only due to brevity (article length) constraints.

D. Analysis of interviews

Finally, we will complete the triangulation of data collection (FECAT results, attitude surveys, interviews) with a discussion of the students' interviews. The questions/statements asked are listed below.

1. I enjoyed chemistry lectures more if they had CQGs.

2. I think that playing CQGs helped me in learning some new chemistry concepts.

3. I think that playing CQGs increased my motivation to learn chemistry.

4. I think that playing CQGs increased my interest in learning chemistry.

5. How did your level of English skills affect your desire to play CQGs?

For interview question 1 (Fig 7a) all interviewees report either "A" or "SA" with the statement that playing CQGs increased their enjoyment. Similarly, in interview question 

the CQGs. We wish to note here, however, that it is hard for students to objectively distinguish between the increase in conceptual knowledge due to the regular traditional coursework and due to CQGs.

375

380

385

400

\section{SIGNIFICANCE AND CONTRIBUTION TO PRACTICE OF CHEMISTRY EDUCATION}

To the best of our knowledge, this is the first multi-semester, two different control groups study on the effectiveness of CQGs in an ESL environment for engineering majors, possibly overall and particularly in the broader MENA context. The study has several (a)

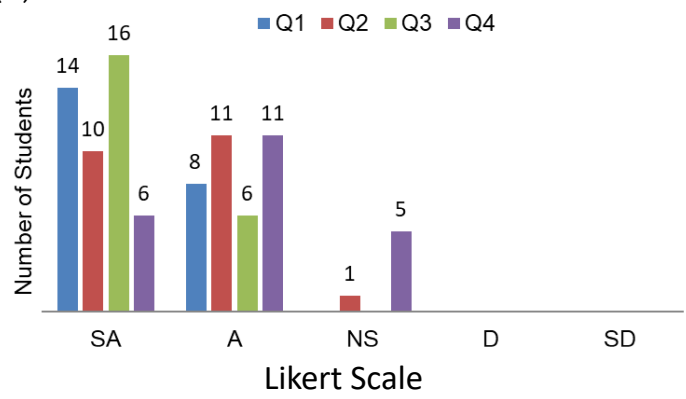
Figure 7. (a) refers to the interview questions
questions 5. (b)

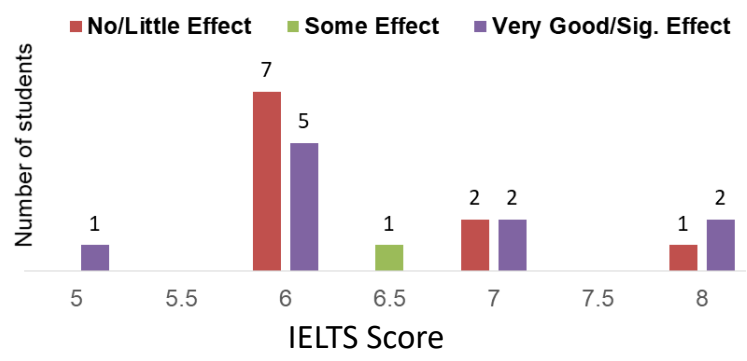

Moving to the interview questions 3 and 4 (still Fig. 7a), the majority of students $(\sim 73 \%)$ report that they feel strongly motivated to study chemistry thanks to, at least in part, CQGs. Answers to the fourth question indicate that, while no students reported decreases in interest to study chemistry due to the CQGs, fewer students reported strong positive effect, compared with the motivation.

In a pair of interview questions where students need to rely on their self-reported skills, students with lower English skills (typically below or at cumulative IELTS score of 6.0), agree that their desire (interest) to looking forward to playing the CQGs, was in part, driven by the lower English skills. Fig. 7(b) indicates that slightly over 50\% of students agree or strongly agree that their lower level of English led to their desire to play CQGs as a compensatory learning mechanism. This last finding points towards the anticipated channel of introducing the computer games in the learning process in ESL science classroom, and in many third world countries, latter being relevant wherever a portion of higher education teaching and learning processes is conducted in English. specific contributions, which may be considered independently, or as mutually supportive of each other. Among these contributions are 10 CQGs (available upon request), tailored to the US-style freshmen engineering chemistry curriculum, and the 
FECAT assessment instrument. The FECAT and a pair of modified CQGs are available in the supporting online information.

While more work remains to be done on the gaming aspects of CQGs, such as modification of the current quiz games for the multiplayer option and enabling online access, the combination of computer- and game-based learning as an interactive engagement supplement to traditional teaching learning in chemistry is clearly worth pursuing. An additional claim to significance stems from the geographical and cultural context; successfully introducing an ESL MENA audience to game-based learning provides some of the strongest evidence yet of the method's widespread applicability. Our results provide a source of information regarding issues in contemporary science education, and may help academic and government education authorities gain insight to quality improvement.

This study contributes to developing a more adequate research-based explanation of the effectiveness of game-based learning, particularly in the chemistry education context, but also in a broader variety of disciplines, and opens space for both instructors and students to augment the traditional teaching and learning.

The "part-time" ( 7\% of weekly class time) interactive engagement method in this report provides an alternative route to improve pedagogical practices in general intro science courses, even at institutions where traditional teaching is entrenched. Even if the role of CQGs proves to be limited, their use may aid in tracking student learning and help instructors offer individualized advice. The systematic, weekly implementation of CQGs enhances student performance in a GenCHEM course.

\section{LIMITATIONS AND FUTURE PERSPECTIVES}

Based on considerable commonality in issues facing college freshmen at various universities in the broader Arabian/Persian Gulf region, a parallel study at several universities would offer additional insights, both by increasing the study population size and by offering the potential for new, more quantifiable observations. While desirable, this is remarkably difficult to administer under the local higher education regulations. A longer period of exposure to the CQGs activity (more than 10 minutes per week) could have provided more insights into various facets effectiveness of the CQGs, but this was not practically feasible.

440 The CQGs presented here are single-player games. We intend to implement multiplayer versions with options including collaborative games, and online multi-player games. As stated in the introduction, this project is motivated by the continuous need to improve and develop learning and testing tools for use in all learning environments, and in support of interactive engagement. There are several common issues across different 
ESL environments [40-43, 55], and further implementation (as multi-player games) may help address some of the ESL issues.

We see a potential for blending computer game based learning (CGBL) in general, and CQGs in particular, with other RBIS [56, 60] (research-based instructional strategies) such as Just-In-Time Teaching (JiTT), concept tests, collaborative and cooperative

450 learning (e.g. peer instruction and think-pair-share). For example, CQGs could be used as a working tool in collaborative learning, or as an initial discussion point in the studio method.

\section{CONCLUSION}

The answers to our research questions are:

1. The 10-min per week approach is an effective strategy to minimize perturbation of the traditional General Chemistry class.

2. For the large fraction of the study population learning gain increased as a function of the IELTS score. Considering that 5.5 - 8.0 IELTS score range covers a broad range of TOEFL values (46-110, approximately), it is understandable that the dependence of the Hake gain on IELTS is not smooth. For a small subset of population above IELTS $=7.0$, the pretest scores are high enough that large gains are not likely.

3. We submit that the test, tentatively named FECAT is a useful general chemistry test, given its acceptable values of KR2O and Cronbach Alpha [42].

4. CQGs and PQs both helped improve students' learning gains compared with students who had neither activity (Semester III). There is a statistically significant difference between chemistry achievement for students in group X (with CQGs) and group Y (with PQ) only for subsets of the overall population (either in separate

5. There is an increase in positive attitude among the CQGs group compared with the PQs group. Interview data also indicated that students' taking CQGs had positive attitudes toward, and motivation and interest to learn chemistry. This is supported by discussion in literature [56-58], which highlights that the greatest educational benefit of computer-assisted instruction could be increased student motivation and improved attitudes, together with [59], where it was reported that games can be used to increase both intrinsic motivation and cognitive growth. 


\section{ASSOCIATED CONTENT}

Supporting Information

A copy of Chemistry Achievement Test, FECAT is available in Supporting Materials. Computer quiz games. Other games are available upon reasonable request from the corresponding author.

\section{AUTHOR INFORMATION}

Corresponding Author

*E-mail: aisakovic@colgate.edu and iregx137@gmail.com

\section{ACKNOWLEDGMENTS}

This study was approved by the KUST Institutional Review Board. We acknowledge the support from the KUST Office of Research Support, M. Hassan, and T. D. Burton (both originally at KUST, Abu Dhabi, now at SUNY and New Mexico State Univ, respectively), and we thank the CHEM-115 teaching team for the assistance in data collection.

\section{REFERENCES}

1. Cousins, A. Gender Inclusivity in Secondary Chemistry: A Study of Male and Female Participation in Secondary School Chemistry. Int. J. Science Education. 2007, 29(6), 711-730.

2. Nbina, J. B.; Viko, B. Effect of Instruction in Metacognitive Self-assessment Strategy on Chemistry Students Self-efficacy and Achievement. Academia Arena. 2010, 2(8), 34-43.

3. Pekdag B. Alternative Methods in Learning Chemistry: Learning with Animation, Simulation, Video and Multimedia. Journal of Turkish Science Education. 2010, 7(2), 79-110.

4. Franco-Marsical, A. J., Olivia-Martinez, J. M., Blanco-Lopez, A., Espana-Ramos, E., A GameBased Approach to Learning the Idea of Chemical Elements and Their Periodic Classification, Journal of Chemical Education 2016, 93, 7, 1173.

5. Eison, J. Using Active Learning Instructional Strategies to Create Excitement and Enhance Learning. $\quad \underline{\text { https://www.cte.cornell.edu/documents/presentations/Eisen-Handout.pdf }}$ (accessed Jul 2017)

6. Balfakih, N. M. A. The Effectiveness of Student Team-achievement Division (STAD) for Teaching High School Chemistry in the United Arab Emirates. International Journal of Science Education. 2003, 25(5), 605-624.

7. Zimmerman, B. Self-regulated Learning and Academic Achievement: An Overview. Educational Psychologist. 1990, 25, 3-17.

8. Gaad, E.; Arif, M.; Scott, F. Systems Analysis of the UAE Education System. International Journal of Educational Management. 2006, 20(4), 291-303.

9. Kurbanoglu, N. I.; Akim, A. The Relationships Between University Students' Chemistry Laboratory Anxiety, Attitudes and Self-efficacy Beliefs. Australian Journal of Teacher Education. 2010, 35(8). 4. 48-59.

10. Stark, R.; Gray, D. Gender Preferences in Learning Science. International Journal of Science Education. 1999, 21(6), 633-643. 
11. Hake, R.R. Interactive-engagement versus Traditional Methods: A Six-thousand Student Survey of Mechanics Test Data for Introductory Physics Courses. American Journal of Physics. 1998, 66, 64-74

12. Eisenkopf, G. Peer Effects, Motivation and Learning. Economics of Education Review. 2010, 29, 364-374.

13. Kollar, I.; Fischer, F. Peer Assessment as Collaborative Learning: A Cognitive Perspective. Learning and Instruction. 2010, 20, 344-348.

14. Afari, E. (2012). Teaching Mathematics in Game Learning Environment. International Review of Contemporary Learning Research. 2012, 1, 33-45.

15. Bragg. L. A. The Impact of Mathematical Games on Learning, Attitudes and Behaviours. Ph.D. Thesis, La Trobe University, Australia, 2006.

16. Chu, R. Ju-chun. How Family Support and Internet Self-efficacy Influence the Effects of Elearning among Higher Aged Adults-analyses of Gender and Age Differences. Computer \& Education. 2010, 55, 255-264.

17. Chang, S. C.; Tung, F. C. An Empirical Investigation of Students' Behavioural Intentions to Use the Online Learning Course Websites. Brit. J. Educational Technology. 2008, 39(1), 71-83.

18. Thompson, L. F.; Meriac, J. P.; Cope, J. G. Motivating Online Performance: The Influences of Goal Setting and Internet Self-efficacy. Social Science Computer Review. 2002, 20(2), 149-159.

19. Yang, Fang-Ying.; Tsai, Chin-Chung. Investigating University Student Preferences and Beliefs about Learning in the Wed-based Context. Computer \& Education. 2008, 50, 1284-1303.

20. Wang, Tzu-Hua. Web-based Quiz-game-like Formative Assessment: Development and Evaluation. Computers \& Education. 2008, 51, 1247-1263.

21. Khine, M. S.; Saleh, I. M. Gameplay Habits among Middle School Students: A Descriptive Study. Journal of Educational Technology Systems. 2009, 34(4), 431-440.

22. Brophy, J. E. On Motivating Students; in Berliner, D.; Rosenshine, B. (Eds.) Talks to Teachers; Random House: New York, 1988; pp 201-245.

23. Schunk, D. H.; Pajares, F. The Development of Academic Self-efficacy; in A. Wigfield A.; Eccles, J. (Eds.); Development of Achievement Motivation; American Press: San Diego, 2001; pp 15-31.

24. Pajares, F. Gender and Perceived Self-efficacy in Self-regulated Learning. Theory into Practice. 2002, 41, 116-125.

25. Davis, T. M.; Shepherd, B.; Zwiefelhofer, T. Reviewing for Exams: Do Crossword Puzzles Help in the Success of Student Learning? The Journal of Effective Teaching. 2009, 9(3), 4-10.

26. Moore, L. S.; Detlaff, A. J. Using Educational Games as a Form of Teaching in Social Work. Arete. 2005, 29(1), 58-72.

27. Nowosielski, D. A. Use of a Concentration Game for Environmental Chemistry Class Review. Journal of Chemical Education. 2007, 84, 239-240.

28. Morris, T. A. Go chemistry: A Card Game to Help Students Learn Chemical Formulas. Journal of Chemical Education. 2011, 88, 1397-1399. 
29. Stringfield, T. W.; Karamer, E. F. Benefits of a Game-based Review Module in Chemistry Course for Nonmajors. Journal of Chemical Education. 2014, 91, 56-58.

30. Bryfczynski, S. P.; Brown, R.; Hester, J.; Herrmann, A.; Koch, D. L.; Copper, M. M.; Grove, N. P. uRespond: iPad as Interactive, Personal Response System. Journal of Chemical Education. 2014, 91, 357-363.

31. Horgan, J. Lecturing for Learning, in a Handbook for Teaching and Learning in Higher Education, $2^{\text {nd }}$ edition; Fry, H., Ketteridge, S.; Marshall, S. Eds.; Routledge Falmer: London, 2003; pp 75.

32. Bullock, D. W.; LaBella, V. P.; Clingan, T.; Ding, Z.; Stewart, G.; Thibado, P. M. Enhancing the Student-Instructor Interaction Frequency. The Physics Teacher. 2002, 40, 30-36.

33. Grabowski, J. J.; Price, M. L. Simple HTML templates for creating science oriented Jeopardy! games for active learning. Journal of Chemistry Education, 2003, 80, 967-976.

34. Kablan, Z. The Effect of Using Exercise-based Computer Games During the Process of Learning on Academic Achievement Among Education Majors. https://files.eric.ed.gov/fulltext/EJ882730.pdf (accessed Jun 2018)

35. Djaouti, D.; Alvarez, J.; Jessel, Jean-Pierre,; Methel, G.; Molinier, P. A Gameplay Definition through Videogame Classification. Int. J. Comp. Game Technology 2008, 470350.

36. Vossen, D. P. 2004. The Nature and Classification of Games. http://people.stfx.ca/dvossen/3CV/AVANTEPaper2004.pdf (last accessed Aug 2019)

37. Wankat, P.; Oreovicz, F. Beyond the Textbook; ASEE Prism, 2003; 8, pp 40 - 42.

38. Mammino, L. The Essential Role of Language Mastering in Science and Technology Education. International Journal of Education and Information Technologies. 2010, 4(3), 139-148.

39. Childs P. E.; Markic, S.; Ryan, M. C. Chemistry Education: Best Practices, Opportunities and Trends, $1^{\text {st }}$ Edition; Wiley-VCH Verlag GmbH \& Co. KGaA, 2015; pp 421-445.

40. Wellington, J.; Osborne, J. Language and Literacy and Science Education; Open University Press: Buckingham, 2001.

41. Rogier, D. The Effects of English-medium Instruction on Language Proficiency of Students enrolled in Higher Education in the UAE. Ph.D. Thesis, the University of Exeter, United Kingdom, 2012.

42. Ling, S. S.; Saffre, F.; Gater, D. L.; Halim. L. Bt.; Isakovic, A. F.; Experimental Development and Implementation of Computer-based Quiz Games in General Chemistry for Engineering; Proceedings of the 2015 IEEE Conference Frontiers in Education, El Paso, TX, USA. 2015.

43. Kebritchi M.; Hirumi A.; Bai, H. The Effects of Modern Mathematics Computer Games on Mathematics Achievement and Class Motivation. Computer \& Education. 2010, 55, 427-443.

44. Vogel, J. J.; Vogel, D. S.; Cannon-Bowers, J.; et al., M. Computer Gaming and Interactive Simulations for Learning: A Meta-analysis. Journal of Educational Computing Research. 2006, 34(3), 229-243.

45. Mitchell, A.; Savill-Smith, C. The Use of Computer Games for Learning. https://dera.ioe.ac.uk/5270/7/041529_Redacted.pdf (last accessed, Jun 08, 2018). 
46. Bloom, B. S., Taxonomy of Educational Objectives, Handbook I - The Cognitive Domain' David McKay Co. Inc. New York, USA, 1956.

47. Ling, S. S. The Effectiveness of Educational Computer Quiz Games on Students' Achievement in and Attitudes ... Ph.D. Thesis, KUST, Abu Dhabi, UAE and National University of Malaysia, Malaysia.

48. Dunn, T. J., Baguley, T.; Brunsden, V. "From Alpha to Omega: A Practical Solution to the Pervasive Problem of Internal Consistency Estimation," British Journal of Psychology, 2014, 105 (3), pp 399-412.

49. George, D., and Mallery, P., SPSS for Windows Step by Step: A Simple Guide and Reference. 11.0 update, 4th edition. Boston: Allyn \& Bacon, 2003.

50. Field, A. Discovering Statistics Using IBM SPSS Statistics. 4th Edition. SAGE Publications Ltd. London. 2003; pp $179-187$.

51. Fraser, B. J. Test of Science-Related Attitudes (TOSRA); Australian Council for Education Research: Melbourne, 1981.

52. Glynn S. M. and Koballa, T. R. Jr. Motivation to Learn College Science, in Mintzes, J. J.; Leonard, W. H. (Eds.); Handbook of College Science Teaching, Arlington, VA: National Science Teachers Association Press, 2006; pp 25-32.

53. Wait, I. W.; Gressel, J. W. Relationship between TOEFL Score and Academic Success for International Engineering Students. Journal of Engineering Education. 2009, 389-398.

54. Borrego, M.; Cutler, S.; Prince, M. J.; Henderson, C.; Froyd, J. E.; Fidelity of Implementation of Research-Based Instructional Strategies in Engineering Science Courses; Journal of Engineering Education. 2013, 394-425.

55. Grow, G. O. Teaching Learners to be Self-directed. Adult Education Quarterly. 1991, 41(3), 125149.

56. Berg, C. A. R. Factors Related to Observed Attitude Change toward Learning Chemistry among University Students. Chemistry Education Research and Practice. 2005, 6(1), 1-18.

57. Bragg, L. Students' Conflicting Attitudes Towards Games as a Vehicle for Learning Mathematics: A Methodological Dilemma. Mathematics Education Research Journal. 2007, $19(1), 29-44$.

58. Hogle J. G. Considering Games as Cognitive Tools: In Search of Effective "Edutainment". http://www.itu.dk/people/petero/Serious\%20Design/games.pdf(accessed Feb 2018).

59. Özmen H. The Influence of Computer-assisted Instruction on Students' Conceptual Understanding of Chemical Bonding and Attitude toward Chemistry: A case for Turkey. Computers \& Education. 2008, 51. 423-438.

60. Mohanam, L. N.; Holton, A. J. Intermolecular Forces Game; Using Card Game to Engage Students in Reviewing Intermolecular Forces, Journal of Chemical Education 2020, 97, 4044. 


\section{CHEMISTRY ACHIEVEMENT PRE-TEST}

Dear students,

a) This test will NOT have any negative impact on your grade, and it is designed in part to help faculty identify areas they need to focus on more in chemistry course.

b) Circle the correct answer clearly. If you wish, you can also write a comment, a calculation and/or explanation of your choice, but you do not have to.

1) What natural phenomenon is the most likely demonstration of a chemical reaction that gives out heat?
A. Earthquake
B. Water freezing
C. Fire
D. Bacteria and viruses
E. Sun

2) A compound is found to have a molar mass of 90 $\mathrm{g} / \mathrm{mol}$ and simplest formula of $\mathrm{C}_{2} \mathrm{H}_{5} \mathrm{O}$. The molecular formula of the substance is:
A. $\mathrm{C}_{3} \mathrm{H}_{6} \mathrm{O}_{3}$
B. $\mathrm{C}_{4} \mathrm{H}_{26} \mathrm{O}$
C. $\mathrm{C}_{4} \mathrm{H}_{10} \mathrm{O}_{2}$
D. $\mathrm{C}_{5} \mathrm{H}_{14} \mathrm{O}$
E. $\mathrm{C}_{4} \mathrm{H}_{10} \mathrm{O}_{4}$

3) Which of the ionic compounds below is NOT likely to be soluble in water?
A. Calcium carbonate
B. Potassium hydroxide
C. Ammonium chloride
D. Magnesium sulfate
E. Lead chloride

4) Which of these is/are the correct unit for the pressure?
A. Pascal $(\mathrm{Pa})$ or Newton $/$ meter $^{2}$
B. Standard atmosphere (atm)
C. Millimeters of mercury column $(\mathrm{mm} \mathrm{Hg})$
D. Bar
E. All of these

5) Which of the following is true about sodium hydroxide?
A. It is not a corrosive substance
B. It is a base that is soluble in water
C. It is strong alkali with a low $\mathrm{pH}$ value
D. It is a weak alkali with a high degree of dissociation E. It is strong alkali that change litmus paper
from blue to red

6) How would you explain chemical properties?

A. Like freezing and boiling

B. Like reactions

C. They describe the way material behaves when acted on by external forces

D. Like gases, liquids and solids

E. Anything that sometimes smells bad

7) Atoms:
A. Exist only in solid materials
B. Are made up of protons, electrons and neutrons
C. Were considered to be the smallest things in the world
D. Can be seen with a microscope
E. Were discovered during World War II

8) Which of the statement below is CORRECT about hydrocarbon compound?
A. It is an organic compound which contains the element of carbon only
B. It is an organic compound containing only carbon and hydrogen
C. This compound is made of carbon-carbon single bonds only
D. This compound consists of elements like carbon and hydrogen and oxygen
E. (C) and (D) only

9) The atomic number of an atom is:
A. The number of electrons
B. The numbers of neutrons
C. The numbers of protons
D. The number of protons plus the number of neutrons
E. The number of protons plus the number of electrons

10) Predict the products of the following acid-base reaction: $\mathrm{HCl}_{(\mathrm{aq})}+\mathrm{NaOH}_{(\mathrm{aq})} \rightarrow$ ?
A. $\mathrm{H}_{3} \mathrm{O}^{+}{ }_{(\mathrm{aq})}+\mathrm{OH}^{-}(\mathrm{aq})$
B. $\mathrm{Na}_{(\mathrm{aq})}^{+}+\mathrm{Cl}_{(\mathrm{aq})}^{-}$
C. $\mathrm{H}_{2} \mathrm{O}_{(\mathrm{l})}+\mathrm{NaCl}_{(\mathrm{aq})}$
D. $\mathrm{NaCl}_{(\mathrm{aq})}+\mathrm{H}^{+}(\mathrm{aq})+\mathrm{OH}_{(\mathrm{aq})}^{-}$
E. No reaction takes place

11) Pure substances:
A. Rarely exist around us
B. Are homogeneous and have unchanging chemical compositions
C. Are heterogeneous and have unchanging chemical compositions
D. Only exist in cubic shape
E. Mostly exist in spherical shape

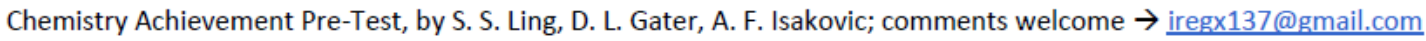


12) An ideal gas law refers to:

$[P$ : pressure, $V$ : volume in Liter;

T: temperature in Kelvin; $\mathbf{n}$ : mol;

$\mathrm{R}$ : gas constant $=8.3145 \mathrm{~J} / \mathrm{mol} \mathrm{K}$ ]
A. $P_{1} V_{1}=P_{2} V_{2}$
B. $P V=n R T$
C. $\frac{P_{1} V_{1}}{T_{1}}=\frac{P_{2} V_{2}}{T_{2}}$
D. $\frac{V_{1}}{T_{1}}=\frac{V_{2}}{T_{2}}$
E. All of these

13) The lowest principal quantum number for an electron is:
A. 0
B. 1
C. 2
D. 3
E. 4

14) A mole is based on the number of:

A. Atoms in 1 gram of pure hydrogen

B. Atoms in 12.000 gram of pure hydrogen

C. Atoms in 12.000 grams of carbon- 12

D. Atoms in 1 grams of carbon-12

E. Atoms in 12.000 grams of carbon-14

15) According to atomic theory, electrons are usually found:
A. In the atomic nucleus
B. Outside the nucleus, but very near it because they are attracted to the protons
C. Outside the nucleus and often far from it - most of an atom's volume is its electron cloud
D. Either in the nucleus or around it - electrons are readily found anywhere in an atom
E. Stuck to the surface of the atom

16) Which of the statements below about electrolyte is INCORRECT?

A. Electrolytes are compounds whose aqueous solutions conduct electricity

B. Non-electrolytes are compounds that cannot conduct electricity either in solid or aqueous solution

C. Strong electrolytes are solutions that are a good conductors of electricity

D. Weak acids or bases are considered weak electrolytes as all the molecules react with water to form ions

E. A non-electrolyte does not conduct electricity because no ions are present in solution.
17) Which of the following statements is FALSE?

A. Alkali metals usually have a +1 oxidation state.

B. Alkali metals form oxides that act as basic anhydrides.

C. Alkali metals form covalent bonds with oxygen.

D. Alkali metals have relatively low first ionization energies.

E. Alkali metals tend to loss it electron to become cations

18) Which electron configuration would you expect to see for a magnesium atom in its ground state?

$$
\begin{array}{ll}
\text { A. } & 1 \mathrm{~s}^{2} 2 \mathrm{~s}^{2} 2 \mathrm{p}^{5} \\
\text { B. } & 1 \mathrm{~s}^{2} 2 \mathrm{~s}^{2} 2 \mathrm{p}^{6} \\
\text { C. } & 1 \mathrm{~s}^{2} 2 \mathrm{~s}^{2} 2 \mathrm{p}^{5} 3 \mathrm{~s}^{2} \\
\text { D. } & 1 \mathrm{~s}^{2} 2 \mathrm{~s}^{2} 2 \mathrm{p}^{6} 3 \mathrm{~s}^{2} \\
\text { E. } & 1 \mathrm{~s}^{2} 2 \mathrm{~s}^{2} 2 \mathrm{p}^{6} 3 \mathrm{~s}^{2} 3 \mathrm{p}^{1}
\end{array}
$$

19) Potassium chloride solution is added to silver (I) nitrate solution in the beaker. The beaker is kept for some time. This is a precipitation reaction. The new precipitate formed in the beaker is:
A. Silver (I) chloride
B. Silver (I) nitrate
C. Silver (II) chloride
D. Potassium nitrate
E. Potassium (II) nitrate

20) Several cubes of ice are added to a warm drink to make the drink cold. This is because:
A. Ice is a good conductor of heat
B. Ice is a poor conductor of heat
C. Ice releases coldness when it melts
D. Ice absorbs heat when it melts
E. Ice has low heat conductivity compare to warm drink

21) Which of the following shows a balanced chemical equation?
A. $\mathrm{CO}_{2(\mathrm{~g})}+2 \mathrm{C}_{(\mathrm{s})} \rightarrow 3 \mathrm{CO}_{(\mathrm{g})}$
B. $\mathrm{Cu}_{(\mathrm{s})}+\mathrm{O}_{2(\mathrm{~g})} \rightarrow \mathrm{CuO}_{(\mathrm{s})}$
C. $2 \mathrm{ZnCO}_{3(\mathrm{~s})} \rightarrow 2 \mathrm{ZnO}_{(\mathrm{s})}+\mathrm{CO}_{2(\mathrm{~g})}$
D. $2 \mathrm{KOH}_{(\mathrm{aq})}+\mathrm{H}_{2} \mathrm{SO}_{4(\mathrm{aq})} \rightarrow \mathrm{K}_{2} \mathrm{SO}_{4(\mathrm{aq})}+2 \mathrm{H}_{2} \mathrm{O}_{(\mathrm{l})}$
E. $\quad 2 \mathrm{CaCO}_{2(\mathrm{~s})}+2 \mathrm{HCl}_{(\mathrm{aq})} \rightarrow 2 \mathrm{CaCl}_{2(\mathrm{aq})}+2 \mathrm{CO}_{2(\mathrm{~g})}+$ $\mathrm{H}_{2} \mathrm{O}_{(1)}$ 
22) Which is TRUE during a phase change, such as water boiling or steel melting?

A. Both temperature and heat energy change

B. Heat energy remains constant but temperature increase or decrease

C. Temperature remains constant but heat is absorbed or released

D. Both temperature and heat energy remain constant

E. Temperature and heat of the energy either both increase or both decrease

23) The diagram below shows a Lewis electron dot structure or Lewis structure of chlorine gas.

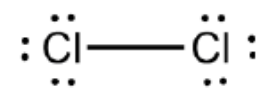

Choose the CORRECT answer/answers.

A. The arrangement of dots indicates the lone pairs of electrons or nonbonding electrons

B. Each chlorine atom has seven valence electrons

C. Chlorine gas has one bond pair between two chlorine atoms

D. (A) and (B) only

E. (A), (B) and (C)

24) A molecular formula is an expression that:

A. Provides us with the total number of moles in a chemical compound

B. Can only be used in derived chemical formuli

C. Is useful to have, but we can just remember them all

D. Useful to have, but it can sometimes be wrong, like for heavy atoms

E. Gives the number of each elemental atom in a molecule

25) A bond between atoms in a molecule is

A. Only a double or triple bond makes sense, since atoms can fly apart if single-bonded

B. Always located in 2s-orbital

C. Made up through sharing of electrons

D. Much stronger than the electrostatic interaction of electrons in atoms

E. Much weaker than electrostatic interaction of electrons in atoms

26) Protons share the space in atomic nucleus with:
A. Molecules
B. Quarks
C. Electrons
D. Neutrons
E. Atoms

27) Which of the following statements is TRUE concerning acids and bases?

A. Acids and bases don't react with each other

B. Acids mixed with bases neutralize each other

C. Acids mixed with bases make stronger bases

D. Acids mixed with bases make stronger acids

E. None of the above

28) Which of the following must be the same before and after a chemical reaction?

A. The sum of the masses of all substances involved

B. The number of molecules of all substances involved

C. The number of atoms of each type involved

D. Both (A) and (C) must be the same

E. Each of the answers (A), (B) and (C) must be the same

29) Which sample contains the greatest number of molecules?
A. $\quad 1.0 \mathrm{~g}$ of $\mathrm{CH}_{4}$
B. $1.0 \mathrm{~g}$ of $\mathrm{H}_{2} \mathrm{O}$
C. $1.0 \mathrm{~g}$ of $\mathrm{HNO}_{3}$
D. $1.0 \mathrm{~g}$ of $\mathrm{N}_{2} \mathrm{O}_{4}$
E. $1.0 \mathrm{~g}$ of $\mathrm{CO}_{2}$

30) A gold necklace is always shiny. This is because:
A. People are more careful handling gold
B. Gold repels dirt
C. Gold does not easily react with the air
D. Gold is valuable
E. Gold can be cleaned easily

31) What is the sign of the enthalpy change for an endothermic reaction?
A. Positive
B. Can't be determined from the information given
C. Negative
D. Depends on the temperature
E. Depends on the pressure

32) All the statements are correct about the oxidation and reduction reaction below EXCEPT

$$
\mathrm{Zn}_{(\mathrm{s})}+\mathrm{H}_{2} \mathrm{SO}_{4(\mathrm{aq})} \rightarrow \mathrm{ZnSO}_{4(\mathrm{aq})}+\mathrm{H}_{2(\mathrm{~g})}
$$
A. The oxidation number of $\mathrm{Zn}$ is zero
B. Hydrogen ions in the acid are reduced to hydrogen gas
C. Zinc acts as reducing agent
D. Hydrogen gas is the oxidizing agent
E. Net ionic equation:

$$
\mathrm{Zn}_{(\mathrm{s})}+2 \mathrm{H}^{+}{ }_{(\mathrm{aq})} \rightarrow \mathrm{Zn}^{2+}{ }_{(\mathrm{aq})}+\mathrm{H}_{2(\mathrm{~g})}
$$

Chemistry Achievement Pre-Test, by S. S. Ling, D. L. Gater, A. F. Isakovic; comments welcome $\rightarrow \underline{\text { iregx137@gmail.com }}$ 
33) Which of the following is NOT a physical property?
A. Blue color
B. Boiling of water
C. Rusting of iron
D. Ocean waves
E. Sand dunes in the wind

34) Changing the number of neutrons of an atom
changes its:
A. Isotope
B. Element
C. Ion
D. Charge
E. Protons

35) Which of the following are all properties of nonmetals?
A. Usually donate electrons easily, typically brittle in the solid form, poor conductors of heat
B. Usually gain electrons easily, poor conductors of heat, poor conductors of electricity
C. Usually gain electrons easily, good conductors of heat and electricity
D. Usually donate electrons easily, metallic luster, good conductors of heat
E. Usually donate electrons easily, gas form and poor conductors of heat

36) The electrons of which element are all spin-paired:
A. Hydrogen
B. Carbon
C. Neon
D. Fluorine
E. Copper 